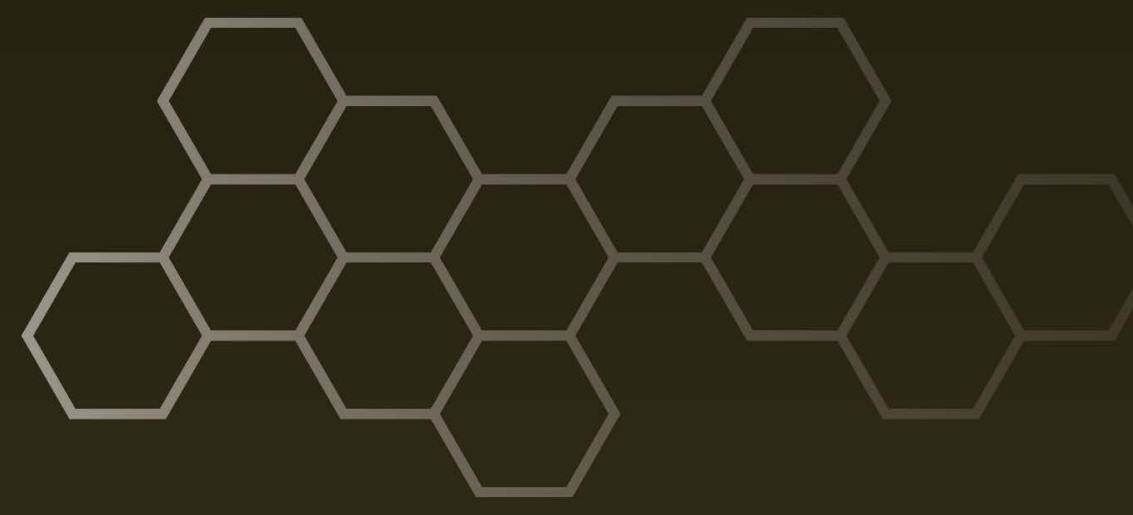

ARL-TR-7235 • MAR 2015

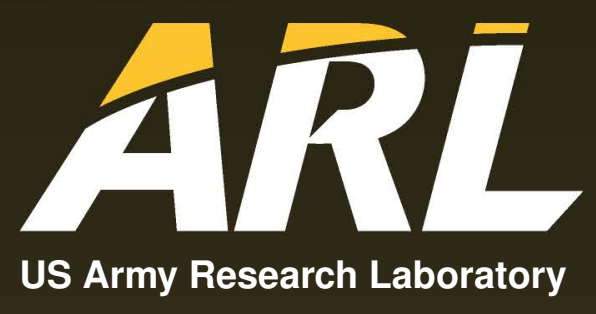

\title{
Evaluation of the Lagrangian Marker Method in CTH: Taylor Impact
}

\author{
by Stephen Schraml
}




\section{NOTICES}

\section{Disclaimers}

The findings in this report are not to be construed as an official Department of the Army position unless so designated by other authorized documents.

Citation of manufacturer's or trade names does not constitute an official endorsement or approval of the use thereof.

Destroy this report when it is no longer needed. Do not return it to the originator. 
ARL-TR-7235 • MAR 2015

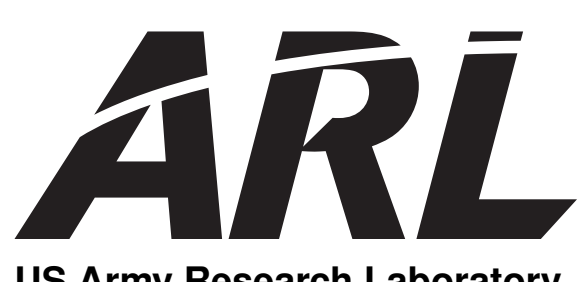

US Army Research Laboratory

\section{Evaluation of the Lagrangian Marker Method in CTH: Taylor Impact}

\section{by Stephen Schraml}

Weapons and Materials Research Directorate, ARL 
Public reporting burden for this collection of information is estimated to average 1 hour per response, including the time for reviewing instructions, searching existing data sources, gathering and maintaining the data needed, and completing and reviewing the collection information. Send comments regarding this burden estimate or any other aspect of this collection of information, including suggestions for reducing the burden, to Department of Defense, Washington Headquarters Services, Directorate for Information Operations and Reports (0704-0188), 1215 Jefferson Davis Highway, Suite 1204, Arlington, VA 222024302. Respondents should be aware that notwithstanding any other provision of law, no person shall be subject to any penalty for failing to comply with a collection of information if it does not display a currently valid OMB control number.

PLEASE DO NOT RETURN YOUR FORM TO THE ABOVE ADDRESS.

\begin{tabular}{|l|l|}
\hline $\begin{array}{l}\text { 1. REPORT DATE (DD-MM-YYYY) } \\
\text { March } 2015\end{array}$ & $\begin{array}{l}\text { 2. REPORT TYPE } \\
\text { Final }\end{array}$ \\
\hline
\end{tabular}

\section{TITLE AND SUBTITLE}

Evaluation of the Lagrangian Marker Method in CTH: Taylor Impact

3. DATES COVERED (From - To)

July 2014-January 2015

5a. CONTRACT NUMBER

5b. GRANT NUMBER

5c. PROGRAM ELEMENT NUMBER

5d. PROJECT NUMBER

AH80

5e. TASK NUMBER

5f. WORK UNIT NUMBER

8. PERFORMING ORGANIZATION REPORT NUMBER

ARL-TR-7235

U.S. Army Research Labo
ATTN: RDRL-WMP-D

Aberdeen Proving Ground, MD 21005-5066

9. SPONSORING/MONITORING AGENCY NAME(S) AND ADDRESS(ES)

10. SPONSOR/MONITOR'S ACRONYM(S)

11. SPONSOR/MONITOR'S REPORT NUMBER(S)

12. DISTRIBUTION/AVAILABILITY STATEMENT

Approved for public release; distribution is unlimited.

13. SUPPLEMENTARY NOTES

\section{ABSTRACT}

A computational study was performed as an initial evaluation of the Lagrangian marker method recently implemented in the CTH shock physics code. A set of Taylor impact experiments served as the basis of this initial evaluation of the method. Numerical simulations of Taylor impact were performed with the CTH marker method, and the final shapes of the impacting cylinders were compared to experimental results. Additional CTH simulations were performed using the legacy Eulerian solver to isolate the influence of the CTH solver on the computational results. Finally, a set of Arbitrary Lagrangian-Eulerian (ALE) finite element simulations was performed for further comparison. The study revealed that the Lagrangian marker method reproduces the Taylor impact results with a degree of fidelity on par with the CTH legacy Eulerian and ALE methods. This study provides a critical first step toward the application of the CTH Lagrangian marker method to ballistic impact problems relevant to defense applications.

\section{SUBJECT TERMS}

impact, penetration, plasticity, fracture, computer simulation

\begin{tabular}{|c|c|c|c|c|c|}
\hline \multicolumn{3}{|c|}{ 16. SECURITY CLASSIFICATION OF: } & \multirow{2}{*}{$\begin{array}{l}\text { 17. LIMITATION } \\
\text { OF } \\
\text { ABSTRACT } \\
\text { UU }\end{array}$} & \multirow{2}{*}{$\begin{array}{l}\text { 18. NUMBER } \\
\text { OF } \\
\text { PAGES } \\
28\end{array}$} & \multirow{2}{*}{$\begin{array}{l}\text { 19a. NAME OF RESPONSIBLE PERSON } \\
\text { Stephen Schraml } \\
\text { 19b. TELEPHONE NUMBER (Include area code) } \\
\text { 410-278-6556 }\end{array}$} \\
\hline $\begin{array}{l}\text { a. REPORT } \\
\text { Unclassified }\end{array}$ & $\begin{array}{l}\text { b. ABSTRACT } \\
\text { Unclassified }\end{array}$ & $\begin{array}{l}\text { c. THIS PAGE } \\
\text { Unclassified }\end{array}$ & & & \\
\hline
\end{tabular}


Contents

List of Figures iv

List of Tables $\quad$ v

Acknowledgments $\quad$ vi

1 Introduction 1

2 Taylor Impact Experiments $\quad 2$

3 Constitutive and Fracture Models 3

3.1 Johnson-Cook 3

3.2 Zerilli-Armstrong 3

3.3 Steinberg-Lund 4

3.4 Johnson-Cook Fracture Model 5

4 Description of Numerical Simulations 6

5 Results for OFHC Copper Impactor 6

6 Results for 4340 Steel (Rc30) Impactor 11

7 Conclusion 15

8 References 17

$\begin{array}{ll}\text { Distribution List } & 19\end{array}$ 


\section{List of Figures}

Fig. 1 Final shape of OFHC copper impactor for experiments and simulations with Johnson-Cook constitutive model (Top: $\mathrm{V}_{\mathrm{s}}=130 \mathrm{~m} / \mathrm{s}$, Bottom:

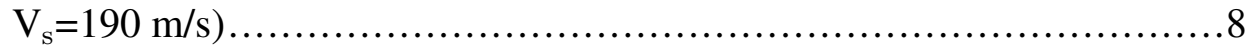

Fig. 2 Final shape of OFHC copper impactor for experiments and simulations with Zerilli-Armstrong constitutive model (Top: $\mathrm{V}_{\mathrm{s}}=130 \mathrm{~m} / \mathrm{s}$, Bottom: $\mathrm{V}_{\mathrm{s}}=190 \mathrm{~m} / \mathrm{s}$ )

Fig. 3 Final shape of OFHC copper impactor for experiments and simulations with Steinberg-Lund constitutive model (Top: $\mathrm{V}_{\mathrm{s}}=130 \mathrm{~m} / \mathrm{s}$, Bottom: $\left.\mathrm{V}_{\mathrm{s}}=190 \mathrm{~m} / \mathrm{s}\right)$

Fig. 4 Final shape of 4340 steel impactor for experiments and simulations with Johnson-Cook constitutive model (Top: $\mathrm{V}_{\mathrm{s}}=208 \mathrm{~m} / \mathrm{s}$, Bottom: $\mathrm{V}_{\mathrm{s}}=343 \mathrm{~m} / \mathrm{s}$ )

Fig. 5 Final shape of 4340 steel impactor for experiments and simulations with Zerilli-Armstrong constitutive model (Top: $\mathrm{V}_{\mathrm{s}}=208 \mathrm{~m} / \mathrm{s}$, Bottom: $\mathrm{V}_{\mathrm{s}}=343 \mathrm{~m} / \mathrm{s}$ )

Fig. 6 Damage in final impactor shape for 4340 steel simulations using Zerilli-Armstrong constitutive model $\left(\mathrm{V}_{\mathrm{s}}=343 \mathrm{~m} / \mathrm{s}\right)$

Fig. 7 Marker simulation results for 4340 steel impactor at $\mathrm{t}=2.9 \mu$ s after impact $\left(\mathrm{V}_{\mathrm{s}}=343 \mathrm{~m} / \mathrm{s}\right.$, Zerilli-Armstrong constitutive model)

Fig. 8 Damage in final impactor shape for 4340 steel marker simulation using Zerilli-Armstrong constitutive model with $\mathrm{D}_{3}=0\left(\mathrm{~V}_{\mathrm{s}}=343 \mathrm{~m} / \mathrm{s}\right) \ldots \ldots \ldots 16$ 


\section{List of Tables}

Table 1 Summary of Taylor impact experiments ..............................2

Table 2 Simulation results for OFHC copper using Johnson-Cook constitutive

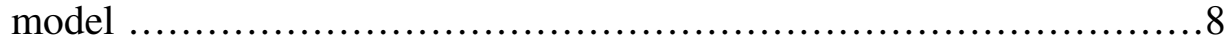

Table 3 Simulation results for OFHC copper using Zerilli-Armstrong constitutive model ........................................................... 9

Table 4 Simulation results for OFHC copper using Steinberg-Lund constitutive model ............................................................. 10

Table 5 Simulation results for 4340 steel using Johnson-Cook constitutive model .......................................................... 12

Table 6 Simulation results for 4340 steel using Zerilli-Armstrong constitutive model .......................................................... 13 


\section{Acknowledgments}

The author gratefully acknowledges the technical input of Richard Leavy and David Kleponis of the US Army Research Laboratory in the preparation of this report. Shane Schumacher and Kevin Ruggirello of Sandia National Laboratories are leading the implementation of the Lagrangian marker method into CTH. The technical assistance provided by Drs Schumacher and Ruggirello in the usage of the method was essential to the successful completion of this study. 


\section{Introduction}

The CTH shock physics code, developed by Sandia National Laboratories, is widely used for defense and industrial applications involving shock waves, large material deformations, and material failure. ${ }^{1}$ In it's original configuration, CTH employs a 2-step solution method; a Lagrangian step followed by a remap step. The remap step, also referred to as the advection step, uses operator-splitting techniques to replace multidimensional equations with a set of 1-dimensional equations. Highresolution interface trackers are used to minimize material dispersion resulting from advection. $^{2}$

Inherent limitations in computational accuracy resulting from advection have provided the motivation for implementing a new computational method into $\mathrm{CTH}^{3}$ As a result, the Lagrangian marker method has recently been implemented into $\mathrm{CTH}$ and offers an alternative to the legacy Eulerian method discussed in the previous paragraph. The primary advantage of this technique over the legacy Eulerian method is the application of a Lagrangian numerical approach to the motion of marker fields rather than using advection to move material through the mesh. The intended result is a computational method with the advantages of a traditional Eulerian method-large material deformations and failure-without the deficiencies associated with material advection. ${ }^{4}$

The implementation of the Lagrangian marker method into CTH marks a significant change to the functionality of the code. The introduction of the new computational method requires evaluation before it can be adopted as a replacement for the legacy Eulerian solution method. The US Army Research Laboratory has begun an initiative to evaluate the CTH Lagrangian marker method for problems in terminal ballistics. The approach taken is to begin with fundamental problems in ballistics, with trusted experimental results, and verify the proper solution to these problems before advancing to the next set of more complicated ballistics problems. ${ }^{3}$

This report describes the initial step in the evaluation of the CTH Lagrangian marker method. The Taylor impact problem ${ }^{5}$ was used as the basis of the study because of the availability of high-quality experimental data and the sensitivity of the experimental result to the constitutive behavior of the impactor, providing an opportunity to verify the proper implementation of constitutive models for metals in the newly implemented method. 
The computational study involved the execution of 3 different sets of numerical simulations to match selected Taylor impact experiments previously reported in literature. CTH simulations were performed using the legacy Eulerian method and then matching simulations were performed using the Lagrangian marker method. These pairs of simulations served to isolate the influence of the marker method on the solution for each case considered. Finally, a set of Arbitrary Lagrangian/Eulerian (ALE) simulations was performed for comparison using the arbitrary Lagrangian/ Eulerian code, ALE3D, developed by the Lawrence Livermore National Laboratory. ${ }^{6}$

\section{Taylor Impact Experiments}

The Taylor impact experiments used in the study involved metallic right-circular cylinders fired into a nearly rigid surface. The impactors considered for the study were made of oxygen-free, high-conductivity (OFHC) copper and 4340 steel (Rc30 hardness) with impact velocities ranging from 130 to $343 \mathrm{~m} / \mathrm{s} .{ }^{7,8}$ Comparing the initial and final shapes of the impactors provides valuable information on the highrate constitutive behavior of the materials. Table 1 provides a summary of the experimental configurations used in the study and the final impactor shapes from the experiments selected. The values listed in the table are the striking velocity $\left(\mathrm{V}_{\mathrm{s}}\right)$, the initial length $\left(\mathrm{L}_{0}\right)$ and diameter $\left(\mathrm{D}_{0}\right)$ of the impactor, the final length $(\mathrm{L})$ and diameter (D) of the impactor, and the final "bulge" of the impactor (W). The bulge is defined by Johnson and Holmquist as the postevent diameter of the impactor measured from a distance of $20 \%$ of the initial length $\left(0.2 \mathrm{~L}_{0}\right)$ from the impact face of the body. ${ }^{9}$

Table 1 Summary of Taylor impact experiments ${ }^{7,8}$

\begin{tabular}{ccccccc}
\hline Material & $\mathbf{V}_{\mathbf{s}}$ & $\mathbf{L}_{\mathbf{0}}$ & $\mathbf{D}_{\mathbf{0}}$ & $\mathbf{L}$ & $\mathbf{D}$ & $\mathbf{W}$ \\
& $(\mathbf{m} / \mathbf{s})$ & $(\mathbf{c m})$ & $(\mathbf{c m})$ & $(\mathbf{c m})$ & $(\mathbf{c m})$ & $(\mathbf{c m})$ \\
\hline \multirow{2}{*}{ OFHC Copper } & 130 & 2.54 & 0.762 & 1.956 & 0.991 & 0.899 \\
& 190 & 2.54 & 0.762 & 1.621 & 1.351 & 1.007 \\
\hline \multirow{2}{*}{ 4340 Steel, Rc30 } & 208 & 2.54 & 0.762 & 2.253 & 1.062 & 0.831 \\
& 343 & 0.81 & 0.762 & 0.631 & 1.147 & 0.912 \\
\hline
\end{tabular}

In a previous study, Johnson and Holmquist developed a metric to provide a single quantitative comparison between Taylor impact experiments and corresponding numerical simulations. This metric is the average error of the final length, diameter, 
and bulge between the experiment and simulation and is represented in Eq. $1,{ }^{9}$ in which $\Delta \mathrm{L}, \Delta \mathrm{D}$, and $\Delta \mathrm{W}$ are the differences between the experimental and computational results. In the current study, this metric is used as the primary means of evaluating the CTH Lagrangian marker method simulation results against the experimental data and the other computational methods.

$$
\bar{\Delta}=\frac{1}{3}\left(\frac{|\Delta L|}{L}+\frac{|\Delta D|}{D}+\frac{|\Delta W|}{W}\right)
$$

\section{Constitutive and Fracture Models}

Three commonly used metal constitutive models were evaluated in the study to verify the proper implementation of each into the CTH Lagrangian marker method.

\subsection{Johnson-Cook}

The Johnson-Cook constutive model, shown in Eqs. 2 and 3 provides a representation of the dynamic yield strength of metals as a function of equivalent plastic strain $\left(\varepsilon_{p}\right)$, plastic strain rate $\left(\dot{\varepsilon}_{p}\right)$, and temperature $(\mathrm{T}) .^{7}$ The model parameters $(\mathrm{A}, \mathrm{B}, \mathrm{n}$, $\mathrm{C}, \mathrm{T}_{\text {melt }}$, and $\mathrm{m}$ ) for OFHC copper and 4340 steel (Rc30) used in the study were derived by Johnson and Cook. ${ }^{7}$

$$
\begin{gathered}
\sigma=\left(A+B \varepsilon_{p}^{n}\right)\left(1+C \ln \frac{\dot{\varepsilon}_{p}}{\dot{\varepsilon}_{0}}\right)\left(1-T^{\prime m}\right) . \\
T^{\prime}=\frac{T-T_{\text {room }}}{T_{\text {melt }}-T_{\text {room }}} .
\end{gathered}
$$

\subsection{Zerilli-Armstrong}

The Zerilli-Armstrong constitutive model is a dislocation-mechanics-based model that incorporates the effects of work hardening, strain-rate hardening, and thermal softening based on thermal activation. ${ }^{10}$ The model takes into consideration grain orientation and includes forms for both face-centered-cubic (fcc) and body- 
centered-cubic (bcc) metals and takes the general form of Eq. 4, in which $\varepsilon_{p}$ is the equivalent plastic strain, $\dot{\varepsilon_{p}}$ is the plastic strain rate, and $\mathrm{T}$ is the temperature.

$$
\sigma=A+\left(C_{1}+C_{2} \sqrt{\varepsilon_{p}}\right) e^{\left(-C_{3} T+C_{4} T \ln \dot{\varepsilon_{p}}\right)}+C_{5} \varepsilon^{n}
$$

The model can be configured for fcc and bcc metals by the selection of the model parameters. For fcc metals, the $\mathrm{C}_{1}$ and $\mathrm{C}_{5}$ parameters are set to zero resulting in the form of Eq. 5 and for bcc metals, the $\mathrm{C}_{2}$ parameter is set to zero resulting in the form of Eq. $6 .{ }^{10}$ The Zerilli-Armstrong model parameters for OFHC copper were obtained from Zerilli and Armstrong, ${ }^{10}$ and the parameters for 4340 steel were obtained from Gray et al., ${ }^{11}$ with the $\mathrm{C}_{1}$ parameter adjusted to obtain the appropriate quasi-static yield strength for a hardness of Rc30.

$$
\begin{gathered}
\sigma_{f c c}=A+C_{2} \sqrt{\varepsilon_{p}} e^{\left(-C_{3} T+C_{4} T \ln \dot{\varepsilon_{p}}\right)} . \\
\sigma_{b c c}=A+C_{1} e^{\left(-C_{3} T+C_{4} T \ln \right)}+C_{5} \varepsilon^{n} .
\end{gathered}
$$

\subsection{Steinberg-Lund}

The Steinberg-Lund constitutive model ${ }^{12}$ is a strain-rate-dependent model derived from the Steinberg-Guinan high-strain-rate constitutive model. ${ }^{13}$ The SteinbergLund model extends the validity of the original Steinberg-Guinan model to strain rates as low as $10^{-4} / \mathrm{s}$. In this model, the yield strength is defined as a function of plastic strain $\left(\varepsilon_{p}\right)$, plastic strain rate $\left(\dot{\varepsilon_{p}}\right)$, pressure $(\mathrm{P})$, and temperature $(\mathrm{T})$ as described in Eqs. 7-10.

$$
\begin{gathered}
\sigma=\left[\sigma_{T}\left(\dot{\varepsilon_{p}}, T\right)+\sigma_{A}\left(1+\beta\left(\varepsilon_{p}+\varepsilon_{i}\right)\right)^{n}\right]\left[\frac{G(P, T)}{G_{0}}\right] . \\
\dot{\varepsilon_{p}}\left(\sigma_{T}, T\right)=\left(\frac{1}{C_{1}} e^{\left[\frac{2 U_{k}}{T}\left(1-\frac{\sigma_{T}}{\sigma_{P}}\right)^{2}\right]}+\frac{C 2}{\sigma_{T}}\right)^{-1} .
\end{gathered}
$$




$$
\begin{gathered}
\frac{G(P, T)}{G_{0}}=1+\frac{A P}{\eta^{\frac{1}{3}}}-B\left(T-T_{r}\right) . \\
\eta=\frac{\rho}{\rho_{0}} .
\end{gathered}
$$

The yield strength in Eq. 7 is expressed in terms of the thermally activated component of the yield strength $\left(\sigma_{T}\right.$, which is a function of the plastic strain rate and temperature), the thermally independent component of the yield strength $\left(\sigma_{A}\right)$, and the local shear modulus $(\mathrm{G})$, which is a function of the pressure and temperature. The thermally activated yield strength is obtained from Eq. 8, which is an expression of the plastic strain rate as a function of the thermally activated yield strength and temperature. The ratio of the local shear modulus to the reference shear modulus is given in Eq. 9, in which $\eta$ is the material compression as expressed in Eq. 10. The terms $\varepsilon_{i}$ and $\mathrm{T}_{\mathrm{r}}$ represent the initial plastic strain and room temperature, respectively. The remaining terms are model constants obtained from Steinberg. ${ }^{14}$

\subsection{Johnson-Cook Fracture Model}

The Johnson-Cook fracture model ${ }^{8}$ was employed in all the CTH Euler and Marker simulations in the study and in the ALE3D simulations using the Johnson-Cook and Zerilli-Armstrong constitutive models. The model defines the local failure strain $\left(\varepsilon_{f}\right)$ as a function of the pressure-stress ratio $\left(\sigma^{*}\right)$, the normalized strain rate $\left(\dot{\varepsilon}^{*}\right)$, and the normalized temperature $\left(\mathrm{T}^{\prime}\right)$ as shown in Eq. 11, in which the normalized temperature is the same as that defined in Eq. 3. The values $D_{1}$ through $D_{5}$ are material model constants derived by Johnson and Cook. ${ }^{7}$

$$
\varepsilon_{f}=\left(D_{1}+D_{2} e^{D_{3} \sigma^{*}}\right)\left(1+D_{4} \ln \left(\dot{\varepsilon}^{*}\right)\right)\left(1+D_{5} T^{\prime}\right)
$$

Damage in the Johnson-Cook fracture model is defined as the ratio of accumulated strain to the failure strain as defined in Eq. 11. When sufficient strain has accumulated such that the damage reaches a value of 1.0, the material at that location is considered to be failed and can no longer support shear. 


\section{Description of Numerical Simulations}

All simulations performed in the study were 2-dimensional (2-D) with axial symmetry. The CTH Euler simulations employed a fixed mesh with a uniform cell size of $0.381 \mathrm{~mm}$, resulting in 10 cells across the radius of the impactor. In the CTH Lagrangian marker method implementation, the markers use the CTH Eulerian mesh as a background grid to track marker motion. ${ }^{4}$ As a result, the resolution of a marker simulation is controlled by both the Eulerian mesh definition and the density of markers per mesh cell. In the CTH marker implementation, marker density is defined as the number of markers per linear dimension in a cell. Thus, for a 2-D simulation, the number of markers per cell is the square of the number of markers per linear dimension, and in a 3-dimensional (3-D) simulation, the number of markers is equal to the cube of the number of markers per linear dimension. From this logic, it is clear that the computational cost of a marker simulation can be strongly dependent upon the marker density.

For this study, all CTH marker simulations used the same mesh as the Eulerian simulations. An initial set of marker simulations was performed using 3 and 6 markers per linear cell dimension, resulting in 9 and 36 total markers per cell in the 2-D simulations. This approach was taken to determine the effect of marker density on simulation convergence. The CTH marker simulation results using 6 markers per cell were nearly identical to the results of the simulations using 3 markers per cell. Consequently, it was decided that for the remainder of the study, 3 markers per cell would be used for all CTH marker simulations and those results are reported herein.

As previously described, ALE simulations were performed to compare to the CTH Euler and marker simulations. The ALE simulations performed in the study used the same mesh size as the CTH simulations, with 10 elements across the radius of the impactor. In these simulations, the finite element mesh was conformal to the outer shape of the impactor and mesh relaxation was enabled on the interior of the impactor body to reduce element distortion in regions of high deformation.

\section{Results for OFHC Copper Impactor}

Numerical simulations were performed to reproduce the conditions of the OFHC copper experiments shown in Table 1. Separate sets of simulations were performed using the 3 constitutive models described earlier. The final impactor shapes from the simulations using the Johnson-Cook, Zerilli-Armstrong, and Steinberg-Lund con- 
stitutive models are shown in Figs. 1, 2, and 3, respectively. Similarly, the tabulated results for the 3 sets of OFHC impactor simulations are summarized in Tables 2, 3, and 4.

The final impactor shapes from the simulations using the Johnson-Cook constitutive model are compared to the experiment in Fig. 1 in which the Euler simulation is on the left, the marker simulations are in the middle, and the ALE simulation in on the right. The simulation results for $\mathrm{V}_{\mathrm{s}}=130 \mathrm{~m} / \mathrm{s}$ are shown on the top of the figure and the results for $V_{s}=190 \mathrm{~m} / \mathrm{s}$ are on the bottom. This figure demonstrates that all of the computational methods produce similar characteristic results: 1) the impact face of the body has a larger diameter than the experiment with the marker simulations producing a greater diameter than the Euler and ALE simulations, 2) the diameter of most of the remainder of the body is less than that of the experiment, and 3) the final length of the body in the simulations is greater than that of the experiment.

The results for the OFHC copper simulations using the Johnson-Cook constitutive model are summarized in Table 2. The experimental measurements of the deformed copper penetrators from Table 1 are also included in this table for comparison. The values of the average error metric $(\bar{\Delta})$ for each simulation in Table 2 show the average error for the marker simulation at each striking velocity is greater than those of the Euler and ALE simulations. Overall, these differences are the result of the impact face of the marker simulations having a greater impact face diameter than the Euler and ALE computational methods.

In conducting similar numerical simulations of these impact events, Johnson and Holmquist made the observation that simulation results for the OFHC copper impactor were improved by using the Zerilli-Armstrong constitutive model in place of the Johnson-Cook model. ${ }^{9}$ Accordingly, it was decided to repeat the previously mentioned simulations for the current study using this model. Fig. 2 illustrates the final shapes of the impactor from these simulations as compared to the experiments, and Table 3 contains a summary of the results. These results confirm the findings of Johnson and Holmquist that the use of the Zerilli-Armstrong constitutive model significantly improved the final impactor shape in the simulations as compared to the experiments. 


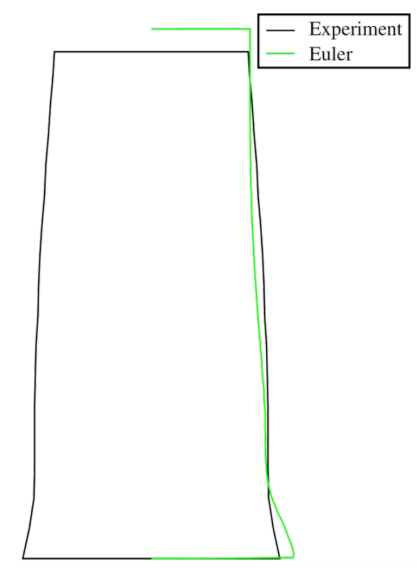

$\mathrm{V}_{\mathrm{s}}=130 \mathrm{~m} / \mathrm{s}$
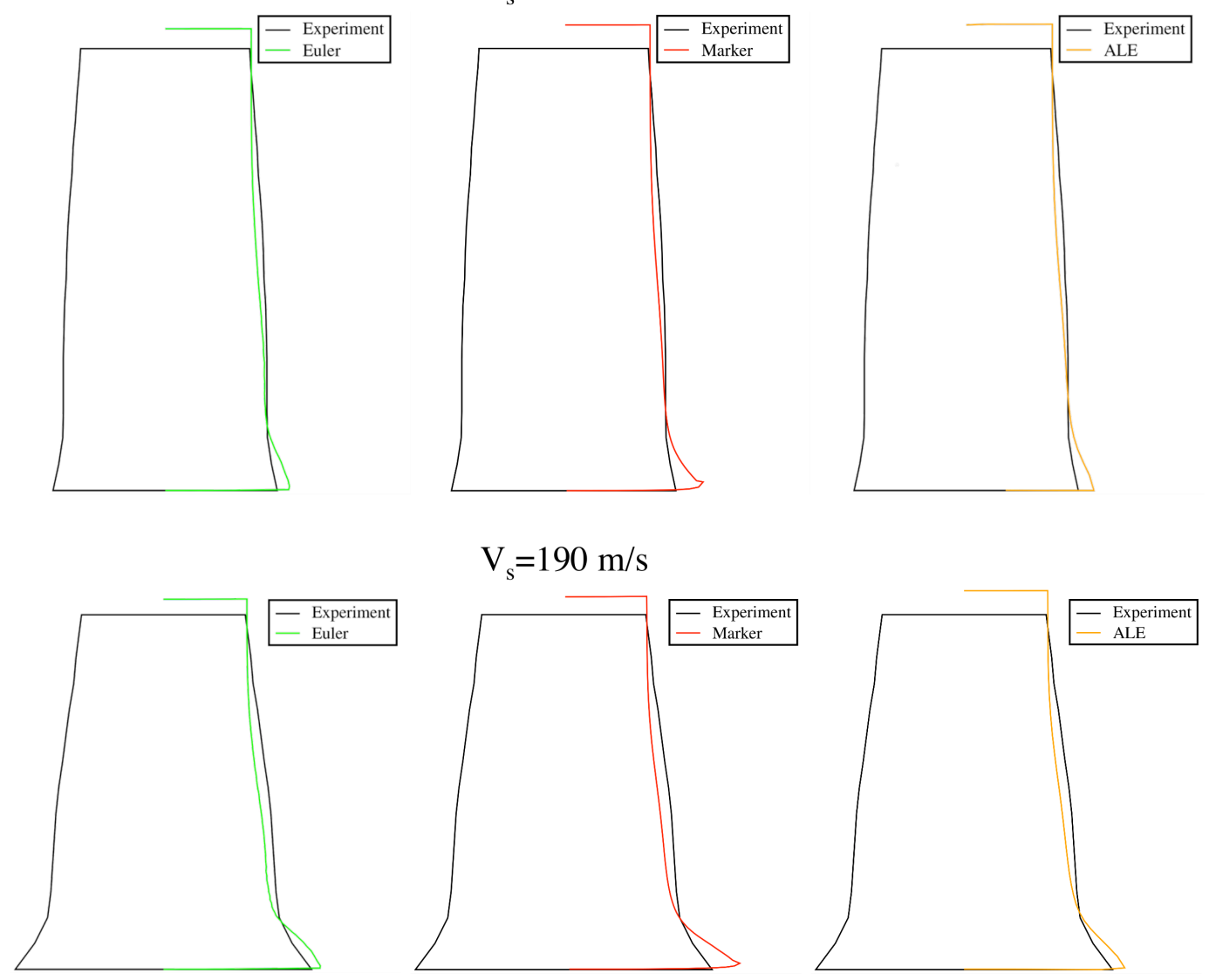

Fig. 1 Final shape of OFHC copper impactor for experiments and simulations with JohnsonCook constitutive model (Top: $V_{\mathrm{s}}=130 \mathrm{~m} / \mathrm{s}$, Bottom: $V_{\mathrm{S}}=190 \mathrm{~m} / \mathrm{s}$ )

Table 2 Simulation results for OFHC copper using Johnson-Cook constitutive model

\begin{tabular}{cccccc}
\hline Method & $\begin{array}{c}\mathbf{V}_{\text {s }} \\
(\mathbf{m} / \mathbf{s})\end{array}$ & $\begin{array}{c}\mathbf{L} \\
(\mathbf{c m})\end{array}$ & $\begin{array}{c}\mathbf{D} \\
(\mathbf{c m})\end{array}$ & $\begin{array}{c}\mathbf{W} \\
(\mathbf{c m})\end{array}$ & $\overline{\boldsymbol{\Delta}}$ \\
\hline Euler & 130 & 2.044 & 1.098 & 0.877 & 0.059 \\
Marker & 130 & 2.060 & 1.231 & 0.880 & 0.105 \\
ALE & 130 & 2.064 & 1.128 & 0.886 & 0.069 \\
Experiment & 130 & 1.956 & 0.991 & 0.899 & $\cdots$ \\
\hline Euler & 190 & 1.692 & 1.431 & 0.933 & 0.059 \\
Marker & 190 & 1.703 & 1.604 & 0.921 & 0.108 \\
ALE & 190 & 1.730 & 1.463 & 0.941 & 0.072 \\
Experiment & 190 & 1.621 & 1.351 & 1.007 & $\cdots$ \\
\hline
\end{tabular}



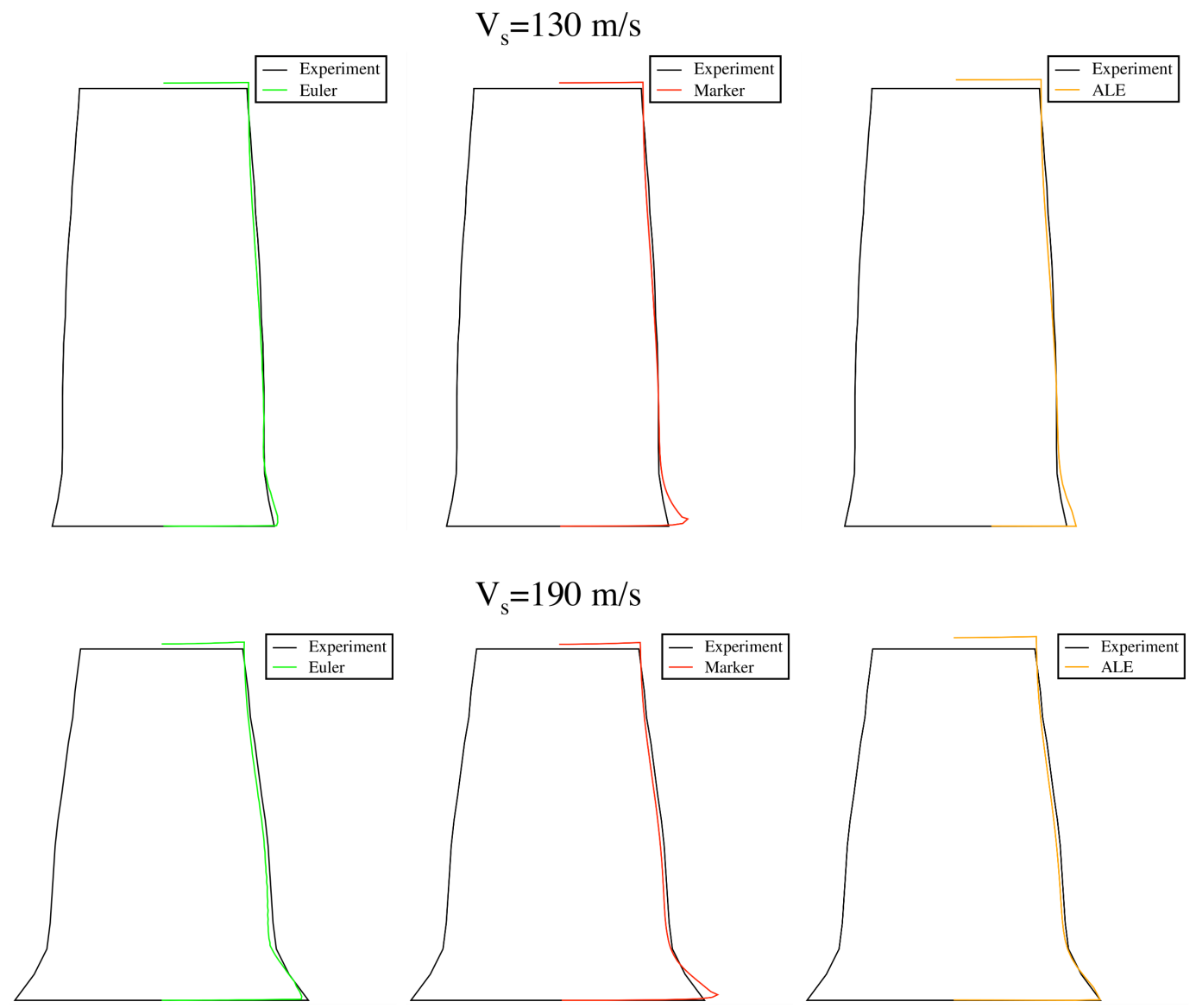

Fig. 2 Final shape of OFHC copper impactor for experiments and simulations with ZerilliArmstrong constitutive model (Top: $V_{\mathrm{s}}=130 \mathrm{~m} / \mathrm{s}$, Bottom: $V_{\mathrm{s}}=190 \mathrm{~m} / \mathrm{s}$ )

Table 3 Simulation results for OFHC copper using Zerilli-Armstrong constitutive model

\begin{tabular}{cccccc}
\hline Method & $\begin{array}{c}\mathbf{V}_{\mathbf{s}} \\
(\mathbf{m} / \mathbf{s})\end{array}$ & $\begin{array}{c}\mathbf{L} \\
(\mathbf{c m})\end{array}$ & $\begin{array}{c}\mathbf{D} \\
(\mathbf{c m})\end{array}$ & $\begin{array}{c}\mathbf{W} \\
(\mathbf{c m})\end{array}$ & $\overline{\boldsymbol{\Delta}}$ \\
\hline Euler & 130 & 1.983 & 1.021 & 0.896 & 0.016 \\
Marker & 130 & 1.984 & 1.162 & 0.903 & 0.064 \\
ALE & 130 & 1.995 & 1.074 & 0.906 & 0.037 \\
Experiment & 130 & 1.956 & 0.991 & 0.899 & $\cdots$ \\
\hline Euler & 190 & 1.651 & 1.291 & 0.973 & 0.032 \\
Marker & 190 & 1.650 & 1.473 & 0.975 & 0.047 \\
ALE & 190 & 1.677 & 1.349 & 0.980 & 0.021 \\
Experiment & 190 & 1.621 & 1.351 & 1.007 & $\cdots$ \\
\hline
\end{tabular}




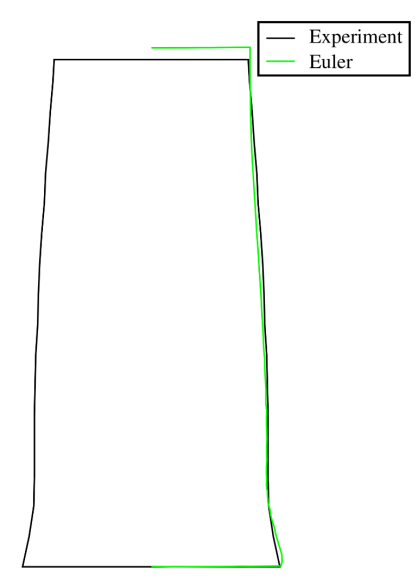

$\mathrm{V}_{\mathrm{s}}=130 \mathrm{~m} / \mathrm{s}$
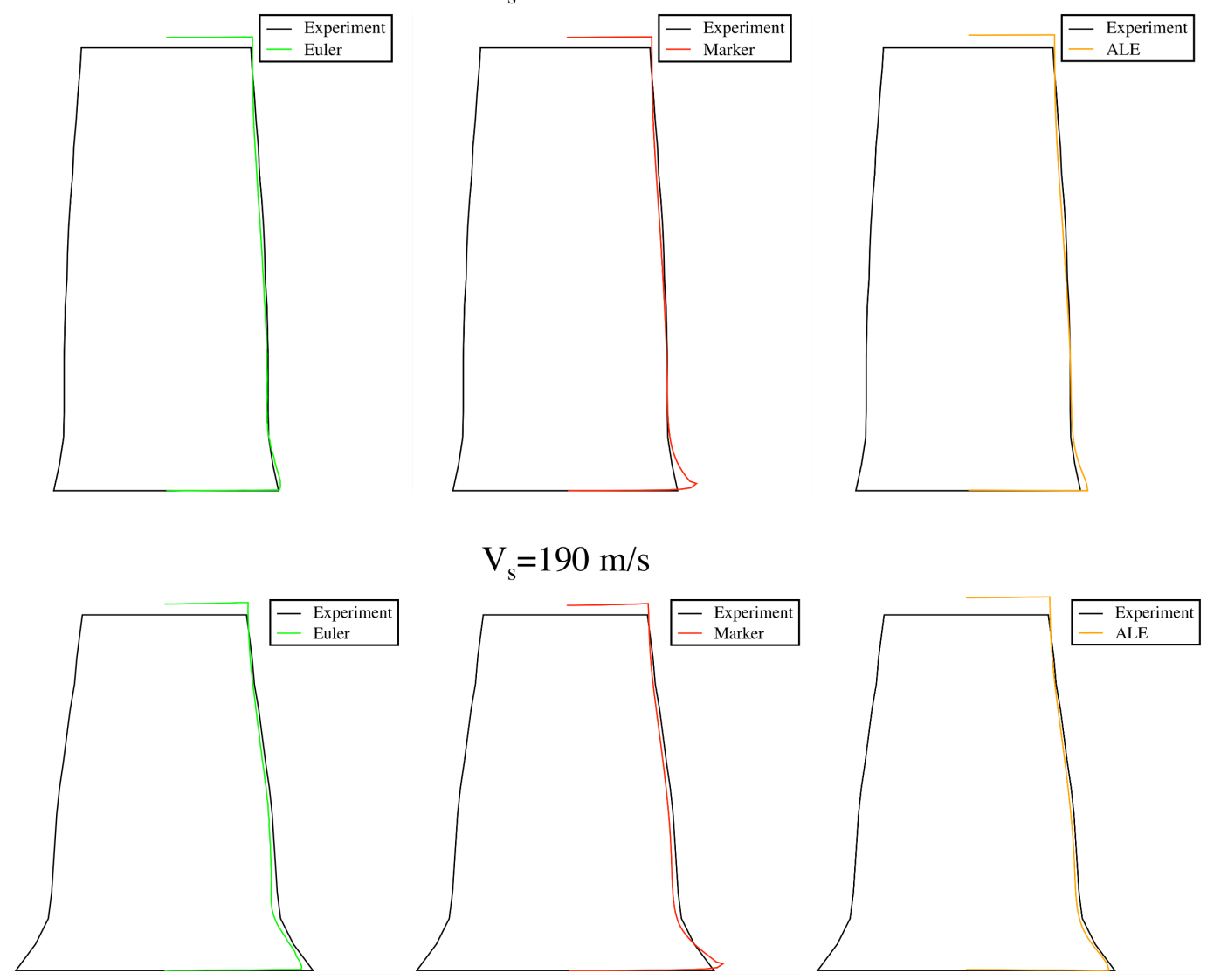

Fig. 3 Final shape of OFHC copper impactor for experiments and simulations with SteinbergLund constitutive model (Top: $V_{\mathrm{s}}=130 \mathrm{~m} / \mathrm{s}$, Bottom: $V_{\mathrm{s}}=190 \mathrm{~m} / \mathrm{s}$ )

Table 4 Simulation results for OFHC copper using Steinberg-Lund constitutive model

\begin{tabular}{cccccc}
\hline Method & $\begin{array}{c}\mathbf{V}_{\mathbf{s}} \\
(\mathbf{m} / \mathbf{s})\end{array}$ & $\begin{array}{c}\mathbf{L} \\
(\mathbf{c m})\end{array}$ & $\begin{array}{c}\mathbf{D} \\
(\mathbf{c m})\end{array}$ & $\begin{array}{c}\mathbf{W} \\
(\mathbf{c m})\end{array}$ & $\overline{\boldsymbol{\Delta}}$ \\
\hline Euler & 130 & 2.003 & 1.008 & 0.891 & 0.017 \\
Marker & 130 & 2.004 & 1.157 & 0.897 & 0.064 \\
ALE & 130 & 2.013 & 1.054 & 0.904 & 0.033 \\
Experiment & 130 & 1.956 & 0.991 & 0.899 & $\ldots$ \\
\hline Euler & 190 & 1.676 & 1.249 & 0.968 & 0.160 \\
Marker & 190 & 1.671 & 1.433 & 0.965 & 0.222 \\
ALE & 190 & 1.703 & 1.298 & 0.982 & 0.038 \\
Experiment & 190 & 1.621 & 1.351 & 1.007 & $\cdots$ \\
\hline
\end{tabular}


Finally, the OFHC copper simulation results using the Steinberg-Lund constitutive model are presented in Fig. 3 and Table 4. These results were nearly identical to the results of the simulations using the Zerilli-Armstrong model, with the SteinbergLund model appearing to result in slightly greater impactor stiffness than the ZerilliArmstrong model.

The simulations using the Zerilli-Armstrong and Steinberg-Lund constitutive models demonstrated a similar characteristic as those in the Johnson-Cook simulations in that the marker method produced a greater impact face diameter than the Euler and ALE methods. Overall, each of the computational methods produced acceptable results as compared to experiment providing a strong indication that the constitutive models are correctly implemented into the CTH Lagrangian marker method.

\section{Results for $\mathbf{4 3 4 0}$ Steel (Rc30) Impactor}

In the next phase of the study, numerical simulations were performed to match the conditions of the 4340 steel impact experiments summarized in Table 1. As before, Euler, marker, and ALE simulations were performed for each impact velocity. Only the Johnson-Cook and Zerilli-Armstrong constitutive models were used in this phase of the study. The Steinberg-Lund constitutive model was not used here because parameters for 4340 steel with a hardness of Rc30 were not readily available for this model. The final shapes of the impactors from the Johnson-Cook simulations are compared to the experimental shapes in Fig. 4, and the tabulated results are shown in Table 5. Similarly, the results for the Zerilli-Armstrong simulations are provided in Fig. 5 and Table 6.

The 4340 steel simulations produced results that are consistent with the characteristics of the OFHC copper simulations. The Zerilli-Armstrong constitutive model produced final impactor shapes that better matched the experiments than the JohnsonCook model. Regarding the average error metric $(\bar{\Delta})$ of the 4340 steel simulations, no single computational method produced the minimum error across the range of impact velocities and constitutive models considered. The overall consistency in the final impactor shapes between the 3 computational methods provides confidence in the proper implementation and functioning of the constitutive models in the marker code. 


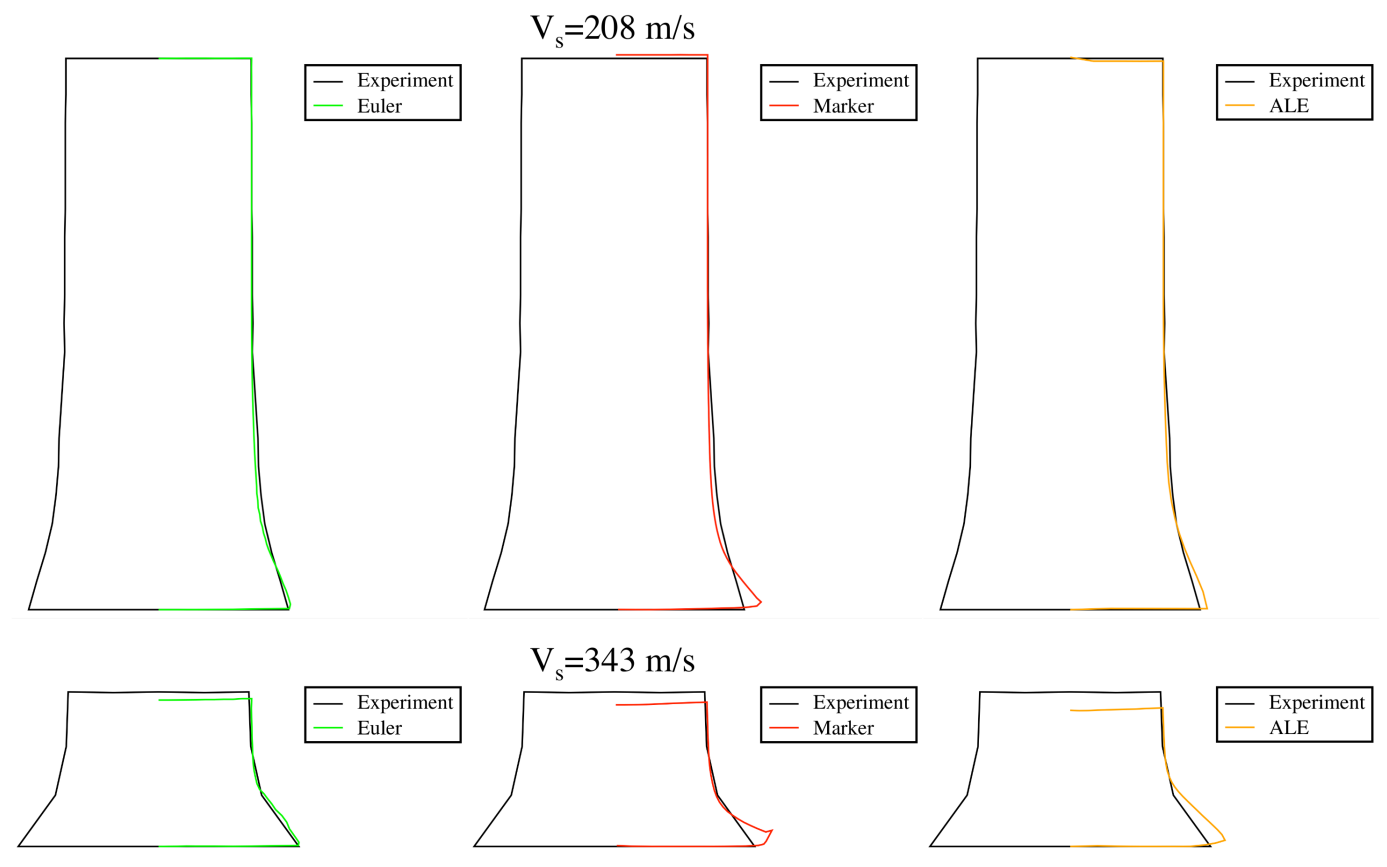

Fig. 4 Final shape of 4340 steel impactor for experiments and simulations with Johnson-Cook constitutive model (Top: $V_{\mathrm{S}}=208 \mathrm{~m} / \mathrm{s}$, Bottom: $V_{\mathrm{S}}=343 \mathrm{~m} / \mathrm{s}$ )

Table 5 Simulation results for 4340 steel using Johnson-Cook constitutive model

\begin{tabular}{cccccc}
\hline Method & $\begin{array}{c}\mathbf{V}_{\mathbf{s}} \\
(\mathbf{m} / \mathbf{s})\end{array}$ & $\begin{array}{c}\mathbf{L} \\
(\mathbf{c m})\end{array}$ & $\begin{array}{c}\mathbf{D} \\
(\mathbf{c m})\end{array}$ & $\begin{array}{c}\mathbf{W} \\
(\mathbf{c m})\end{array}$ & $\overline{\boldsymbol{\Delta}}$ \\
\hline Euler & 208 & 2.253 & 1.078 & 0.802 & 0.013 \\
Marker & 208 & 2.268 & 1.199 & 0.792 & 0.057 \\
ALE & 208 & 2.257 & 1.119 & 0.809 & 0.027 \\
Experiment & 208 & 2.253 & 1.062 & 0.831 & $\cdots$ \\
\hline Euler & 343 & 0.604 & 1.147 & 0.941 & 0.025 \\
Marker & 343 & 0.589 & 1.288 & 0.887 & 0.072 \\
ALE & 343 & 0.566 & 1.266 & 1.006 & 0.103 \\
Experiment & 343 & 0.631 & 1.147 & 0.912 & $\cdots$ \\
\hline
\end{tabular}




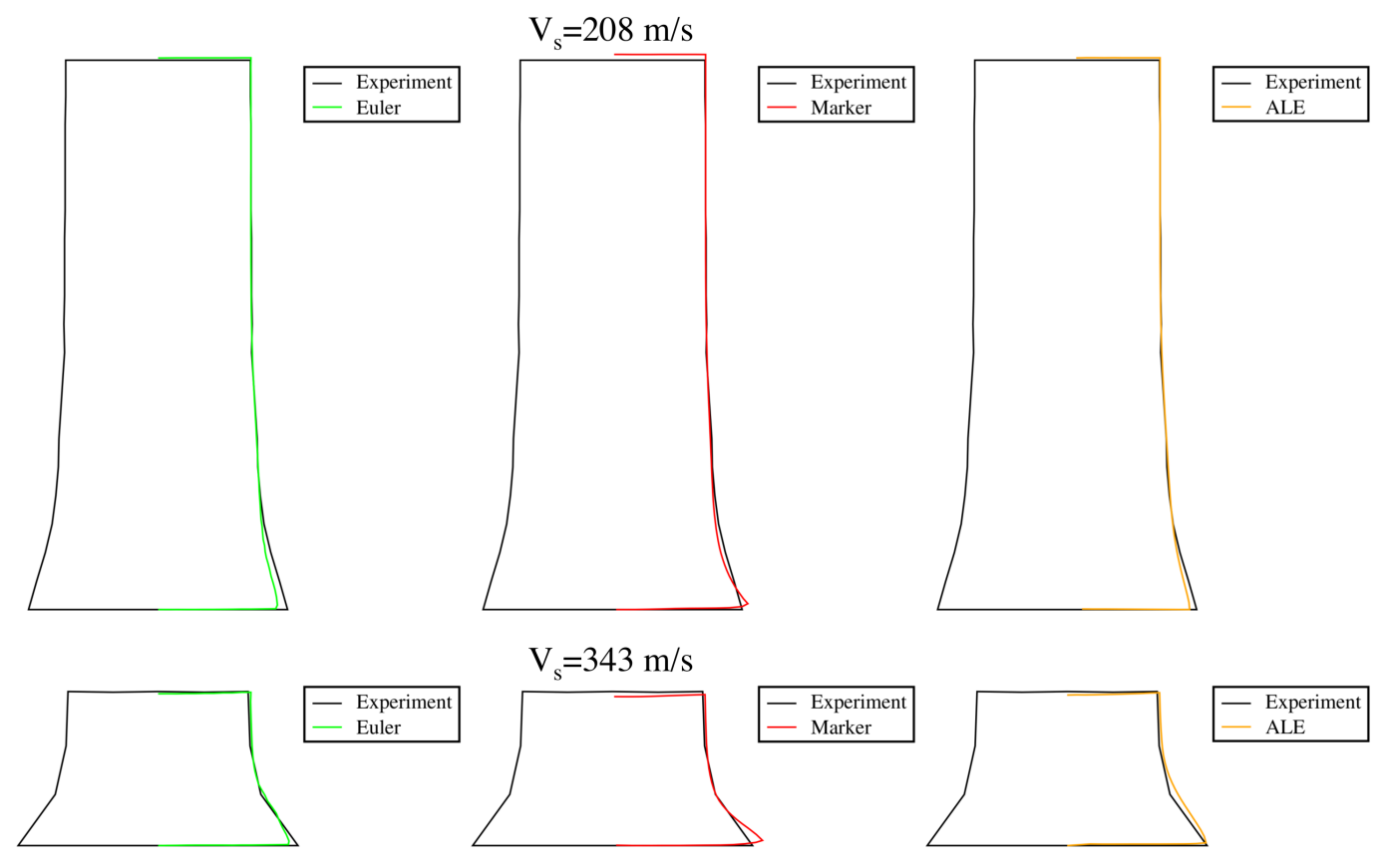

Fig. 5 Final shape of $\mathbf{4 3 4 0}$ steel impactor for experiments and simulations with ZerilliArmstrong constitutive model (Top: $V_{\mathrm{s}}=208 \mathrm{~m} / \mathrm{s}$, Bottom: $V_{\mathrm{s}}=343 \mathrm{~m} / \mathrm{s}$ )

Table 6 Simulation results for $\mathbf{4 3 4 0}$ steel using Zerilli-Armstrong constitutive model

\begin{tabular}{cccccc}
\hline Method & $\begin{array}{c}\mathbf{V}_{\mathbf{s}} \\
(\mathbf{m} / \mathbf{s})\end{array}$ & $\begin{array}{c}\mathbf{L} \\
(\mathbf{c m})\end{array}$ & $\begin{array}{c}\mathbf{D} \\
(\mathbf{c m})\end{array}$ & $\begin{array}{c}\mathbf{W} \\
(\mathbf{c m})\end{array}$ & $\overline{\boldsymbol{\Delta}}$ \\
\hline Euler & 208 & 2.263 & 0.978 & 0.828 & 0.029 \\
Marker & 208 & 2.277 & 1.109 & 0.818 & 0.023 \\
ALE & 208 & 2.263 & 1.004 & 0.840 & 0.023 \\
Experiment & 208 & 2.253 & 1.062 & 0.831 & $\cdots$ \\
\hline Euler & 343 & 0.628 & 1.074 & 0.927 & 0.028 \\
Marker & 343 & 0.619 & 1.228 & 0.906 & 0.032 \\
ALE & 343 & 0.626 & 1.139 & 0.975 & 0.066 \\
Experiment & 343 & 0.631 & 1.147 & 0.912 & $\cdots$ \\
\hline
\end{tabular}


For each of the impactor materials and constitutive models considered, the marker simulations produced a noticeably greater impact face diameter than the experiments and the other simulation methods for both impact velocities considered. This increased impact face diameter is a result of material failure in the marker simulations that does not occur as extensively in the other computational methods. This effect is illustrated in Fig. 6 which shows the distribution of damage in the final shape of the 4340 steel impactor for the simulations using the Zerilli-Armstrong constitutive model for $\mathrm{V}_{\mathrm{s}}=343 \mathrm{~m} / \mathrm{s}$. The damage in the Euler simulation is well below 1.0 - the value at which the material is considered to be failed and can no longer support shear. The damage in the ALE simulation is almost entirely below the failure level, with only a small portion of the impact face exhibiting failure. However, in the marker simulation, nearly the entire impact face is failed, resulting in a larger amount of radial deformation as compared to the Euler and ALE simulations. Furthermore, failure in the marker simulation also occurs away from the impact face, which is not observed in the Euler and ALE simulations.
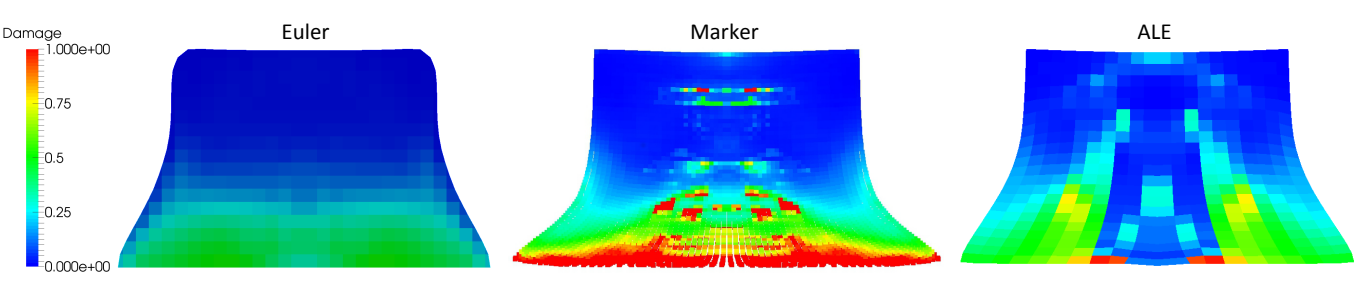

Fig. 6 Damage in final impactor shape for 4340 steel simulations using Zerilli-Armstrong constitutive model $\left(V_{\mathrm{s}}=343 \mathrm{~m} / \mathrm{s}\right)$

Examination of the early deformation behavior of the impactor provides insight into the cause of the increased extent of failure in the marker simulation as compared to the Euler and ALE simulations. The length of the 4340 steel impactor used in the $V_{\mathrm{s}}=343 \mathrm{~m} / \mathrm{s}$ experiment was $8.13 \mathrm{~mm}$. For a wave speed of $4.6 \mathrm{~mm} / \mu \mathrm{s}$, the time for a shock wave to propagate from the impact face to the rear of the body is approximately $1.77 \mu \mathrm{s}$. Fig. 7 provides images of the deformed body at a time of $2.9 \mu$ s after impact-sufficient time for a shock wave to travel to the rear of the body and a rarefaction wave to begin traveling back toward the impact face. 


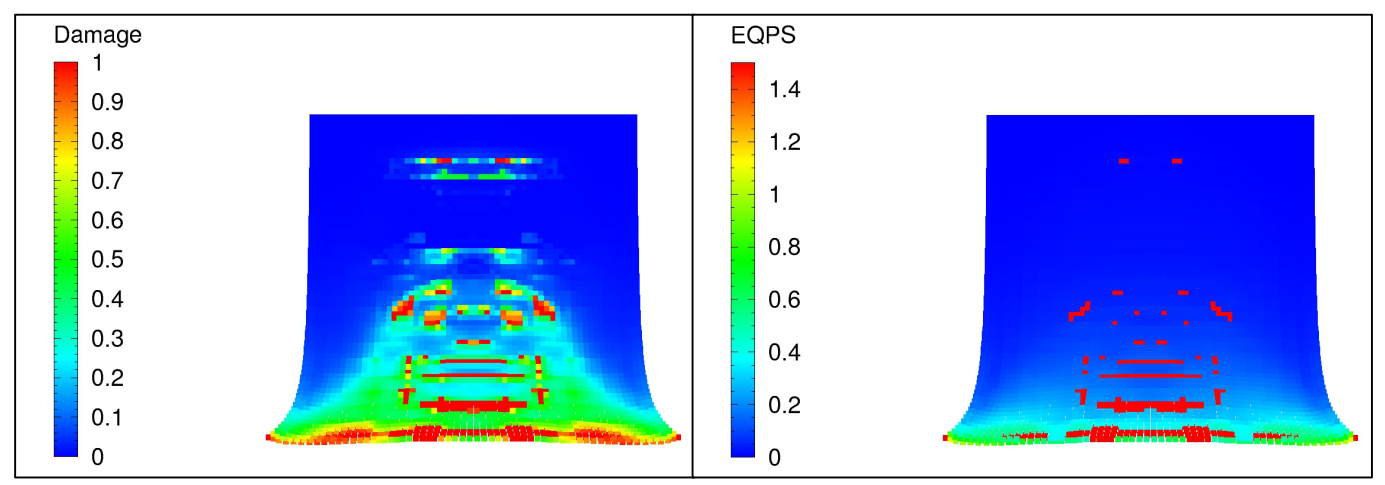

Fig. 7 Marker simulation results for 4340 steel impactor at $t=2.9 \mu \mathrm{s}$ after impact $\left(V_{\mathrm{S}}=\mathbf{3 4 3} \mathrm{m} / \mathrm{s}\right.$, Zerilli-Armstrong constitutive model)

The image on the left side of Fig. 7 shows regions of localized damage forming as a result of the shock wave propagation through the body. The image on the right of the figure shows regions of high equivalent plastic strain occurring at the failure sites after the initial shock wave has propagated through the body. These images demonstrate a dependence of the Johnson-Cook fracture model behavior on the computed pressure field. To test this hypothesis, an additional marker simulation was performed using the Zerilli-Armstrong constitutive model in which the pressure-stress coefficient in the Johnson-Cook fracture model $\left(\mathrm{D}_{3}\right.$ in Eq. 11$)$ was set to zero to eliminate the pressure-dependent portion of the fracture model. Fig. 8 is a plot of the final shape of the impactor from this simulation which shows only minimal failure at the impact surface, and no failure interior to the body. This result confirms the assumption that the excessive failure in the marker simulations was a result of the coupling between the pressure field and the Johnson-Cook fracture model.

\section{Conclusion}

A computational study was performed to evaluate the functionality of the Lagrangian marker method recently implemented into the CTH shock physics code. Simulations were performed to reproduce the conditions of selected Taylor impact experiments to verify the proper implementation of 3 commonly used metal constitutive models in the CTH Lagrangian marker method. Additional simulations were performed using the legacy CTH Eulerian method and an arbitrary LagrangianEulerian code to compare material response and isolate the influences of computational method and constitutive model on the overall results. 

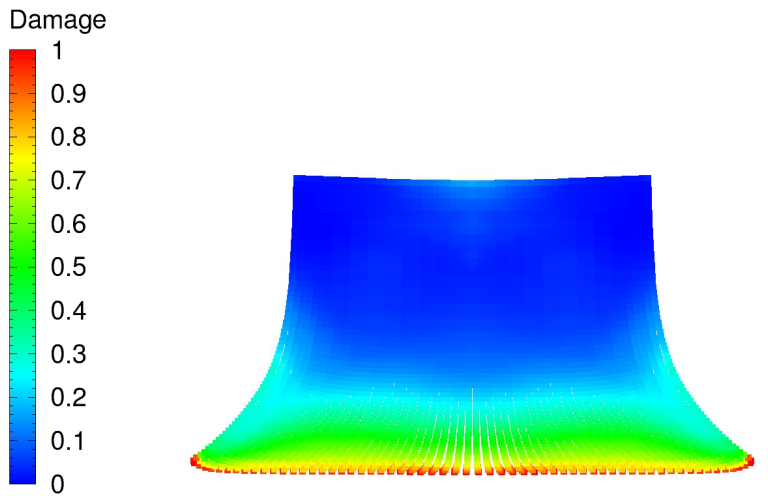

Fig. 8 Damage in final impactor shape for 4340 steel marker simulation using ZerilliArmstrong constitutive model with $D_{3}=0\left(V_{\mathrm{s}}=343 \mathrm{~m} / \mathrm{s}\right)$

The study results demonstrated overall consistent material response between the 3 computational methods for each of the constitutive models evaluated, indicating correct implementation of the constitutive models in the marker method. Simulations using the CTH Lagrangian marker method consistently resulted in greater impact face deformation than the other 2 methods. Investigation of the data revealed that the marker simulations had a greater degree of material failure than the Euler and ALE simulations. This material failure in the marker simulations is caused by the initial shock wave propagation through the material and is therefore related to the relationship between the equation of state and the fracture model. This coupling between the computation of the pressure field and the fracture model requires further investigation before the CTH Lagrangian marker method can be applied to a wider range of problems in terminal ballistics. 


\section{References}

1. McGlaun J, Thompson S. CTH: A three-dimensional shock wave physics code. International Journal of Impact Engineering. 1990;10:351-360.

2. Kimsey K, Schraml S, Hertel E. Scalable computations in penetration mechanics. Advances in Engineering Software. 1998;29(3-6):209-215.

3. Bolling D. Evaluation of the material point method within CTH to model 2dimensional plate impact problems. U.S. Army Research Laboratory; 2014 September. Report No.: ARL-MR-0880.

4. Schumacher S, Ruggirello K. CTH reference manual: Marker technologies. Albuquerque (NM): Sandia National Laboratory; 2013 March. Report No.: SAND2013-1675.

5. House J. Taylor impact testing. Eglin AFB (FL): Air Force Armament Laboratory; 1989 January. Report No.: AFATL-TR-89-41.

6. Nichols A. Users manual for ALE3D: An arbitrary Lagrange/Eulerian 2D and 3D code system. Livermore (CA): Lawrence Livermore National Laboratory; 2010 Jun. Report No.: LLNL-SM-433954.

7. Johnson G, Cook W. A constitutive model and data for metals subjected to large strains, high strain rates and high temperatures. In: Ballistics; 1983 Apr19-21; The Hague, The Netherlands. p. 541-547.

8. Johnson G, Holmquist T. Test data and computational strength and fracture model constants for 23 materials subjected to large strains, high strain rates, and high temperatures. Los Alamos (NM): Los Alamos National Laboratory; 1989. Report No.: LA-11463-MS.

9. Johnson G, Holmquist T. Evaluation of cylinder-impact test data for constitutive model constants. Journal of Applied Physics. 1988;64(8):3901-3910.

10. Zerilli F, Armstrong R. Dislocation-mechanics-based constitutive relations for material dynamics calculations. Journal of Applied Physics. 1987;61(5):18161825 .

11. Gray G, Chen S, Wright W, Lopez M. Constitutive equations for annealed metals under compression at high strain rates and high temperatures. Los Alamos (NM): Los Alamos National Laboratory; 1994. Report No.: LA-12669-MS. 
12. Steinberg D, Lund C. A constitutive model for strain rates from $10^{-4}$ to $10^{6} \mathrm{~s}^{-1}$. Journal of Applied Physics. 1989;65(4):1528-1533.

13. Steinberg D, Cochran S, Guinan M. A constitutive model for metals applicable at high-strain rate. Journal of Applied Physics. 1980;51(3):1489-1504.

14. Steinberg D. Equation of state and strength properties of selected metals. Livermore (CA): Lawrence Livermore National Laboratory; 1991 February. Report No.: UCRL-MA-106439. 


\begin{tabular}{|c|c|c|}
\hline 1 & DEFENSE TECHNICAL & B AYDELOTTE \\
\hline$(\mathrm{PDF})$ & INFORMATION CTR & D MALLICK \\
\hline & DTIC OCA & C MEYER \\
\hline 2 & DIRECTOR & $\begin{array}{l}\text { D SCHEFFLER } \\
\text { B SCHUSTER }\end{array}$ \\
\hline$(\mathrm{PDF})$ & US ARMY RESEARCH LAB & RDRL WMM B \\
\hline & RDRL CIO LL & B LOVE \\
\hline & IMAL HRA MAIL \& RECORDS MGMT & RDRL WMP A \\
\hline 1 & GOVT PRINTG OFC & S BILYK \\
\hline$(\mathrm{PDF})$ & A MALHOTRA & $\begin{array}{c}\text { RDRL WMP B } \\
\text { K ZIEGLER }\end{array}$ \\
\hline 3 & NAVSEA DAHLGREN & RDRL WMP C \\
\hline (PDF) & W CHEPREN & R BECKER \\
\hline & C DYKA & B LEAVY \\
\hline & M HOPSON & S SEGLETES \\
\hline & & RDRL WMP D \\
\hline 9 & SANDIA NATIONAL LABORATORIES & W CLARK \\
\hline$(\mathrm{PDF})$ & S ATTAWAY & D KLEPONIS \\
\hline & A BRUNDAGE & H MEYER \\
\hline & A GULLERUD & F MURPHY \\
\hline & E HERTEL & C RANDOW \\
\hline & J KORBIN & J RUNYEON \\
\hline & D LITTLEWOOD & G VUNNI \\
\hline & K MISH & M ZELLNER \\
\hline & S SCHUMACHER & RDRL WMP E \\
\hline & S SILLING & B CHAMISH \\
\hline & & D HORNBAKER \\
\hline 2 & LLNL & J HOUSKAMP \\
\hline$(\mathrm{PDF})$ & D FAUX & RDRL WMP G \\
\hline & R MCCALLEN & R BANTON \\
\hline & & J STEWART \\
\hline 4 & SOUTHWEST RESEARCH INSTITUTE & \\
\hline (PDF) & C ANDERSON & \\
\hline & G JOHNSON & \\
\hline & T HOLMQUIST & \\
\hline & J WALKER & \\
\hline 1 & UNIV OF ALABAMA BIRMINGHAM & \\
\hline$(\mathrm{PDF})$ & D LITTLEFIELD & \\
\hline 2 & DSTL & \\
\hline (PDF) & A MEARNS & \\
\hline & J CORDELL & \\
\hline & ABERDEEN PROVING GROUND & \\
\hline 26 & DIR USARL & \\
\hline (PDF) & $\begin{array}{l}\text { RDRL CIH S } \\
\text { J CAZAMIAS }\end{array}$ & \\
\hline & RDRL WML H & \\
\hline
\end{tabular}


INTENTIONALLY LEFT BLANK. 